\title{
Proprioceptive neuromuscular facilitation (PNF) and its impact on vascular function
}

\author{
Celia Escobar-Hurtado, PT, MSc ${ }^{1}$, Robinson Ramírez-Vélez, PT, PhD²
}

\section{SUMMARY}

Recent studies of intervention in sedentary subjects, or those with neurological lesions, suggest that increased motor activity (exercise/physical activity), performed at moderate intensities and habitually, could have beneficial effects on the vascular function. However, the physiological effects of interventions conducted with facilitating techniques of the motor activity, such as Kabat's proprioceptive neuromuscular facilitation techniques (PNF) on vascular function are unknown, even though such physiological effects are proposed in said postulates. This report presents the usefulness of PNF on vascular function in three healthy volunteers. The patterns of Kabat's PNF increase, just like the models or contractile isotonic activity proposed in this test, the tension of vascular friction, which relates to better vascular function.

Keywords: Vascular function; Endothelium; Proprioceptive neuromuscular facilitation (PNF).

Colomb Med. 2011; 42: 373-8

La facilitación neuromuscular propioceptiva (FNP) y su impacto sobre la función vascular

\section{RESUMEN}

Estudios recientes de intervención en sujetos sedentarios o con lesiones neurológicas, sugieren que un aumento de la actividad motora (ejercicio/actividad física) realizado a intensidades moderadas y de manera habitual, podría tener efectos benéficos en la función vascular. Sin embargo, se desconocen los efectos fisiológicos de intervenciones realizadas con técnicas facilitadoras de la actividad motora, como las técnicas de facilitación neuromuscular propioceptiva (FNP) de Kabat, sobre la función vascular, aun cuando se proponen dentro de sus postulados tales efectos fisiológicos. Este informe, describe la utilidad de la FNP sobre la función vascular, en tres voluntarios saludables. Los patrones de FNP de Kabat, al igual que los modelos de actividad contráctil isotónica propuestos en esta prueba, incrementan la tensión de roce vascular, la cual se relaciona con una mejor función y distensibilidad vascular.

Palabras clave: Función vascular; Endotelio; Facilitación neuromuscular propioceptiva.

Colomb Med. 2011; 42: 373-8

Kabat's Proprioceptive Neuromuscular Facilitation (PNF) is a system to promote the normal responses of the neuromuscular mechanism, consisting in the use of techniques of proprioceptive stimulation to activate (facilitate) or relax (inhibit) specific muscle groups ${ }^{1}$. It is based on the neurophysiology principles, indicated by Sherrington, of successive induction, innervations, reciprocal inhibition, and the phenomenon of irradiation. PNF integrates the use of spiral and diagonal patterns specific of movement (of antagonist, agonist muscles) with procedures (muscular stretching, resistance, others) and superimposed techniques that induce the muscular contraction, or else, promote relaxation and, thereafter, permit increasing articular mobility and muscle strength, physiological results made clear by changes in blood flow ${ }^{1}$. Since their development in the 1940s and 50s, their effects have been founded on the utilization of basic procedures and specific techniques based on

1. Full Professor, School of Human Rehabilitation, Universidad del Valle.Cali, Colombia.e-mail: celesh_351@hotmail.com

2. PhD Student, Biomedical Sciences, Department of Physiological Sciences, Biochemistry. Universidad del Valle, Cali, Colombia. e-mail: robin640@hotmail.com

Received for publication June 10, 2009 Accepted for publication October 19, 2010 

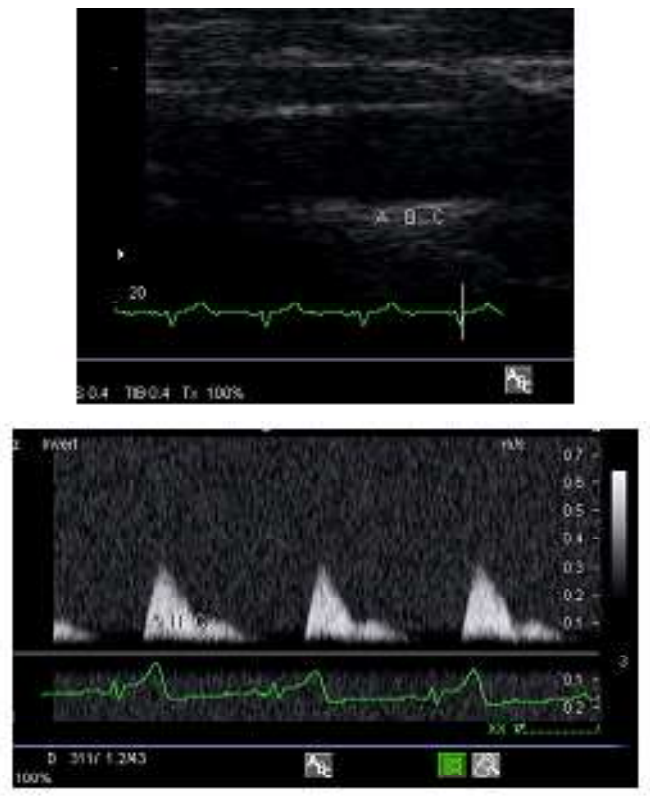
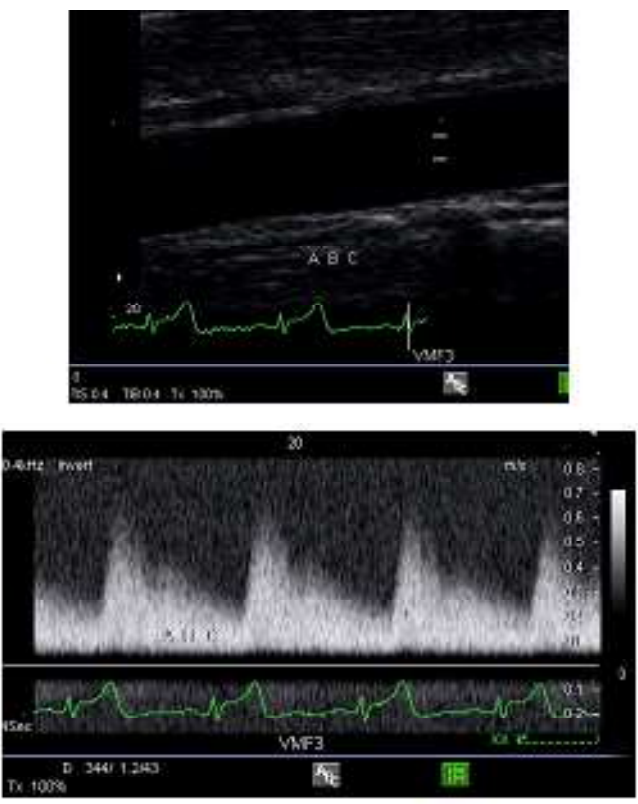

Figure 1. Evaluation of endothelial function and vascular parameters

neurophysiologic principles related to the neuromuscular mechanism, which are superimposed to defined patterns of movement and posture among the ones the subject uses in daily life activities, seeking provoke or improve muscular contraction ${ }^{1,2}$.

These effects have been evaluated and recent studies in sedentary subjects, or those with neurological lesions, suggest that increased motor activity (exercise/physical activity) performed at moderate intensities and on a regular basis could have beneficial effects on vascular function, given that activation of the large muscle groups favors the increase of blood flow during their performance, which leads to increased friction on the vascular endothelium and, therefore, greater release of vasoactive substances, generating greater vascular dilation. However, the effect of interventions performed with Kabat's PNF on arterial function is unknown even though variant effects are postulated in its physiological enunciates. The objective of this work was to describe the impact of two PNF techniques on vascular function.

\section{CLINICAL CASE}

The clinical case is about three male, apparently healthy, volunteer subjects, belonging to a university health program of the city of Cali, Colombia, average age $19.3+0.5$ years, body weight $61.3 \pm 6.8 \mathrm{~kg}$, height
$177.6 \pm 7 \mathrm{~cm}$, and Body Mass Index (BMI) $19.4 \pm 1.3 \mathrm{~kg} /$ $\mathrm{m}^{2}$. Before being included, the participants were informed about the intervention. They provided their consent willingly and received an explanation about the tests. The variants of interest of the study, were taken at the start and after each intervention; the participants were given tests of acute response to the exercise (vascular and endothelial function) by means of the Flow-Mediated Dilatation (FMD) test (dependent variant $)^{3}$, a technique comprising the visualization of the brachial artery, measuring its diameter and the speed of blood flow, (independent variants) through images for vascular plethysmography. These tests were applied after a diet free of nitrites and nitrates 12 hours before the measurements, abstinence from cigarettes and physical activity (variants of confusion). The brachial artery was measured above the anterocubital pit in longitudinal plane, using a lineal gamma transducer $(12 \mathrm{MHz})$. The diameter of the brachial artery was determined initially at rest and post interventions, and blood flow was estimated by the average time of the signal obtained from the Doppler speed (Figure 1). Additionally, in each test hemodynamic signs (EKG, $\mathrm{HR}$ and $\mathrm{BP}$ ) were taken (independent variants).

The participants were then randomly assigned to three interventions defined for the study as patterns of movement (Intervention Models) (Figure 2, Tables 1, 

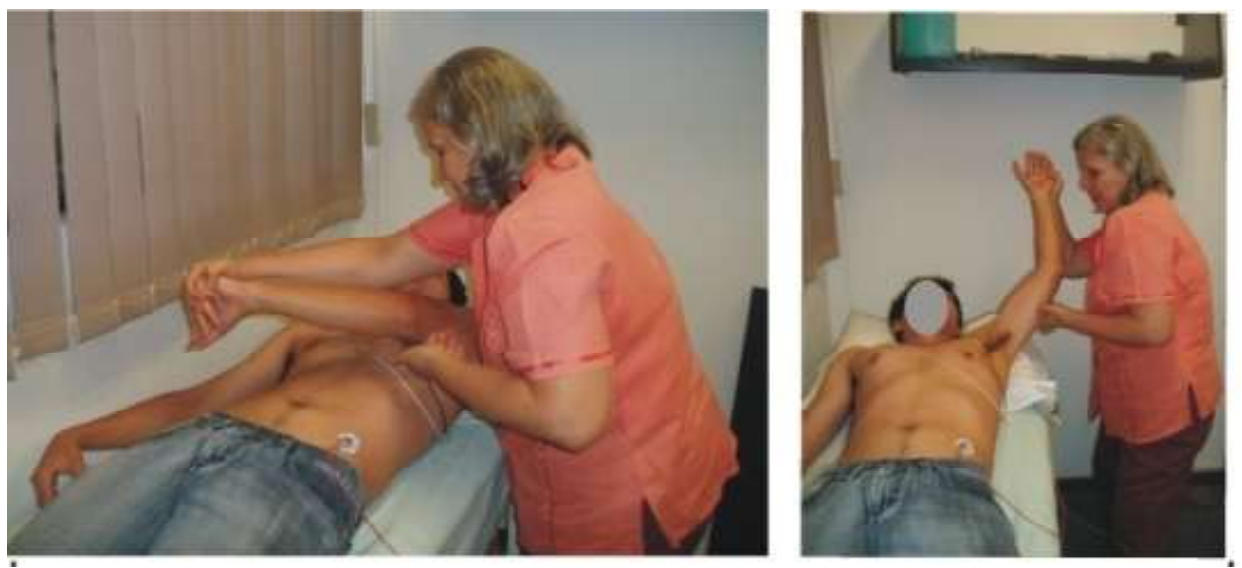

Model 1
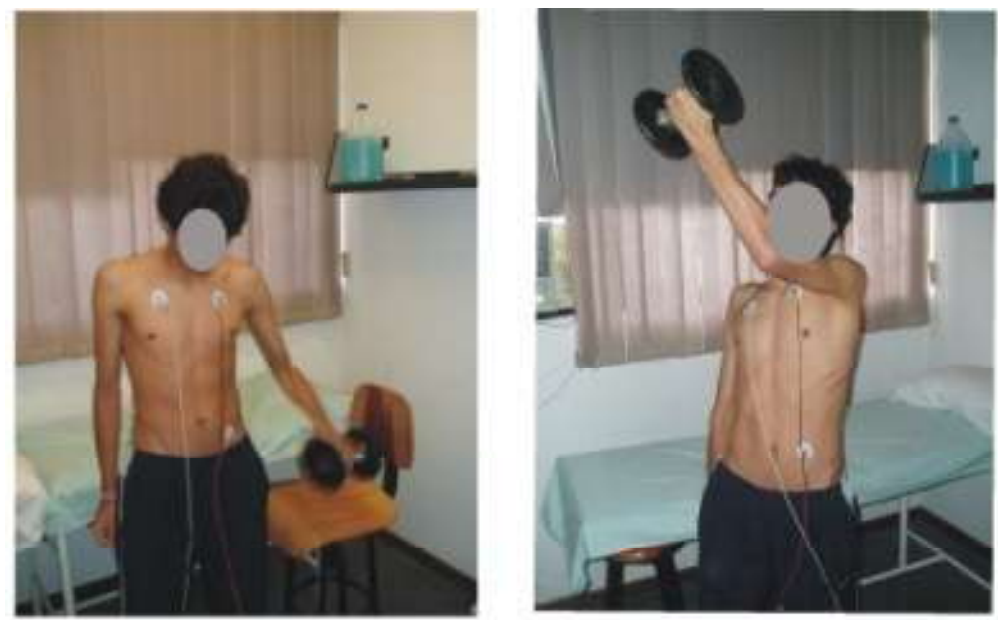

Model 2
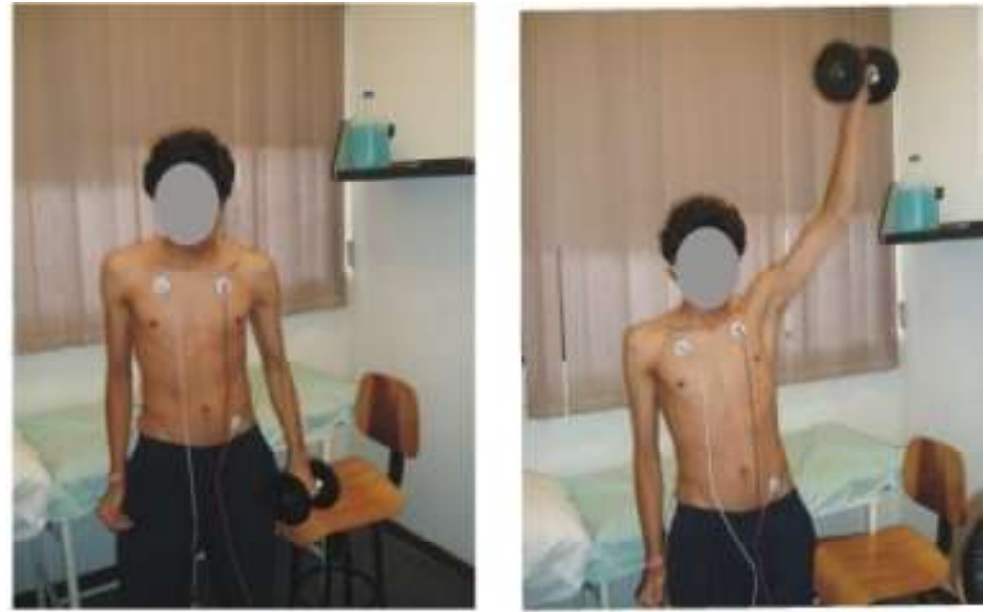

Model 3

Figure 2. Patterns of movement (intervention models) utilized in the study 
Table 1

Clinical and anthropometric characteristics of subjects evaluated

\begin{tabular}{lcccc}
\hline \multicolumn{1}{c}{ Characteristics } & Subject I & Subject II & Subject III & Total mean (DE) \\
\hline Age (years) & & & & \\
Weight (kg) & 19.0 & 20.0 & 19.0 & $19.3 \pm 0.5$ \\
Height (cm) & 59.0 & 56.0 & 69.0 & $61.3 \pm 6.8$ \\
Body mass index $\left(\mathrm{kg} / \mathrm{m}^{2}\right)$ & 171.0 & 177.0 & 185.0 & $177.6 \pm 7.0$ \\
Percentage of fat & 20.1 & 17.8 & 20.1 & $19.4 \pm 1.3$ \\
Waist circumference (cm) & 15.5 & 10.2 & 11.1 & $12.3 \pm 2.8$ \\
Hip circumference (cm) & 74.0 & 70.0 & 75.0 & $73.0 \pm 2.6$ \\
Waist-hip relation & 91.5 & 88.0 & 94.0 & $91.2 \pm 3.0$ \\
SBP rep. (mm Hg) & 0.81 & 0.80 & 0.80 & $0.80 \pm 0.05$ \\
DBP rep. (mm Hg) & 130.0 & 122.0 & 125.0 & $125.6 \pm 4.0$ \\
HR rep. (Ipm) & 80.0 & 71.0 & 66.0 & $72.3 \pm 7.0$ \\
HR post (Ipm) & 66.0 & 57.0 & 65.0 & $62.6 \pm 4.9$ \\
EDD (\%) & 84.0 & 62.0 & 68.0 & $71.3 \pm 11.3$ \\
nEDD (\%) & 5.7 & 21.2 & 11.4 & $12.7 \pm 7.8$ \\
EDDP (\%) & 22.9 & 36.4 & 42.9 & $34.0 \pm 10.2$ \\
\hline
\end{tabular}

Systolic Blood Pressure rest: (SBP rest); Diastolic Blood Pressure rest: (DBP rest); Heart Rate rest: (HR rest); Heart Rate Postintervention: (CF post); Endothelium-Dependent Dilation: (EDD); non-Endothelial Dependent Dilation: (nEDD); EndotheliumDependent Dilation Post-intervention: (EDDP).

2) Model 1. Application, by physiotherapist experienced in the PNF techniques, of the techniques of «Reversal of Antagonists» (RA), superimposed on the implementation of the flexor and extensor patterns of Diagonal 1 in the left upper limb (LUL) and, subsequently, of the Diagonal 2 (LUL), in the manner and sequence described below: Slow Reversal - Hold Technique, superimposed to the patterns of movement in D1 flexion and D1 extension, of the LUL. The application of this technique was initiated in the entire length of each diagonal pattern and continued execution in decreasing patterns lengths in the mentioned patterns, until stabilized in an intermediate point of the length, where proceeded with the Rhythmic Stabilization Technique (five sets of six repetitions of each technique were performed in the sequence described above). Once the above activities were completed, the same selection of techniques, with the same sequence, proceeded to applied to the patterns of Diagonal 2 (D2 flexion and extension D2). Model 2. Application of the Diagonals D1 (flexion and extension) and D2 (flexion and extension) of Kabat on patterns of free active movement for upper extremity (left side with free weight at $60 \%$ of the Maximum Muscular Resistance (MR), previously calculated. Model 3. Application of isotonic exercise in open kinetic chain (no spiral component-nor diagonal on upper left extremity) with free weight at $60 \%$ of the MR. This intervention was performed during four consecutive days. The nonintervened arm of the same subject was considered control.

The results were presented in measures of central tendency and dispersion, recorded in the SPSS 15.0 statistic package for Windows (Graphpad Instat, Graphpad Software, University of London, London, UK).

\section{RESULTS AND DISCUSSION}

Motor or physical activity conditions an increase in arterial compliance, changes in arterial tension, plasmatic lipids, lipoproteins, and metabolism in general, effects considered protectors for the onset of primary and secondary cardiovascular effects ${ }^{4}$. Such compliance can be determined by the vascular index or FMD, which 
Table 2

Changes in vascular function of participants

\begin{tabular}{|c|c|c|c|}
\hline Variables & Subject I & Subject II & Subject III \\
\hline Basal arterial diameter $(\mathrm{mm})$ & 3.5 & 3.3 & 3.5 \\
\hline DPI Model $1(\mathrm{~mm})$ & 3.3 & 3.5 & 4.4 \\
\hline DPI Model 2 (mm) & 2.6 & 3.5 & 4.7 \\
\hline DPI Model 3 (mm) & 3.7 & 3.6 & 4.8 \\
\hline Model 1 change $\%$ & -5.7 & 5.7 & 25.7 \\
\hline Model 2 change $\%$ & -25.7 & 5.7 & 34.2 \\
\hline Model 3 change $\%$ & 5.7 & 9.0 & 37.1 \\
\hline Basal flow (ml/min) & 24.0 & 26.0 & 28.0 \\
\hline FPI Model 1 (ml/min) & 47.0 & 57.0 & 62.0 \\
\hline FPI Model 2 (ml/min) & 17.0 & 37.0 & 56.0 \\
\hline FPI Model 3 (ml/min) & 39.0 & 34.0 & 31.0 \\
\hline Model 1 change $\%$ & 95.8 & 119.0 & 121.4 \\
\hline Model 2 change $\%$ & -29.1 & 42.3 & 100.0 \\
\hline Model 3 change $\%$ & 62.5 & 30.7 & 10.7 \\
\hline Basal arterial diameter $(\mathrm{mm})$ & 3.5 & 3.3 & 3.5 \\
\hline DAC Model $1(\mathrm{~mm})$ & 3.1 & 2.9 & 3.7 \\
\hline DAC Model $2(\mathrm{~mm})$ & 3.5 & 2.9 & 3.3 \\
\hline DAC Model 3 (mm) & 3.4 & 2.9 & 3.7 \\
\hline \% CPI Model 1 & -11.4 & -12.1 & 5.7 \\
\hline \% CPI Model 2 & 0.0 & -12.1 & -5.7 \\
\hline \% CPI Model 3 & -2.8 & -12.1 & 5.7 \\
\hline Basal flow (ml/min) & 24.0 & 26.0 & 28.0 \\
\hline Arm control flow(ml/min) & 24.0 & 23.0 & 32.0 \\
\hline Arm control flow(ml/min) & 30.0 & 26.0 & 26.0 \\
\hline Arm control flow (ml/min) & 19.0 & 27.0 & 25.0 \\
\hline$\%$ CPI Model 1 & 0.0 & -11.5 & 14.2 \\
\hline \% CPI Model 2 & 25.0 & 0.0 & -7.1 \\
\hline \% CPI Model 3 & -20.8 & 3.8 & -10.7 \\
\hline
\end{tabular}

Diameter Post-Intervention: (DPI); Flow Post-intervention: (FPI); Diameter Arm Control (DAC); Change Post-intervention: (CPI).

has been commonly utilized ${ }^{3}$ in clinical studies as an indicator of the vascular and endothelial function, being capable of identifying patients at high cardiovascular risk because it reflects arterial integrity. Reports of research works have equally verified the effect of aerobic exercise: when aerobically trained men and sedentary ones are compared; the prior ones present a preserved FMD in relation (or as opposed) to the sedentary ones ${ }^{4}$. This effect was found in each of the participants in this case report, in the following way: By comparing the results of each participant's basal measurements with measurements made after every intervention (Model 1, Model 2 and Model 3) the following values, expressed in percentage of change, were found for each case: Subject I, respecting the arterial diameter a $-5.7 \%$ of change with Model 1, $-25.7 \%$ with Model 2 and a $5.7 \%$ of change with Model 3. In subject II, there was a $5.7 \%$ of change with Models $1 \& 2$ and a $9 \%$ of change in Model 3. In subject III, there was a $25.7 \%$ of change with Model $1,34.2 \%$ of change 
with Model 2, and 37.1\% of change with Model 3. As for vascular flow, in subject I there was a $95.8 \%$ of change with Model 1, $-29.1 \%$ of change with Model 2, and a $62.5 \%$ of change with Model 3. In subject II, there was a $119 \%$ of change with Model 1, 42.3\% of change with Model 2, and a 30.7\% of change with Model 3. Finally, in subject III, there was a $121.4 \%$ of change with Model 1, 100\% of change with Model 2, and a $10.7 \%$ of change with Model 3 (Table 2).

Currently, the effect of interventions performed with patterns and techniques of Kabat's PNF on the vascular function and arterial compliance is unknown, but in the evidence the benefits of physical activity over the modification on the cardio-metabolic risk factors are attributed to the change in the metabolic and vascular function ${ }^{4}$. At the vascular level, the endothelium presents unique responses to the forces of blood flow: the pulsating flow and the friction stress are physiological stimulus responsible, in part, for the basal liberation of vasoactive substances such as Nitric Oxide (NO). These events happen during regular contractile muscular activity and are proportional to its intensity.

It is, thereby, proposed that the PNF techniques by Kabat ${ }^{4,5}$, used in this work, like the contractions induced by the muscular isotonic activity (Model 1 vs. Model 3), generate the same hemodynamic forces, made clear by the changes observed in this case report in the plethysmographic parameters such as arterial flow, vascular diameter, endothelium-dependent dilation, and non-endothelium-dependent dilation.

\section{CONCLUSION}

As the models of isotonic contractile activity proposed in this Test, Kabat's techniques of PNF used in this study increment the stress of vascular friction, which is related to a better vascular function. This tension of friction can directly affect the vascular morphology, and correlation has been demonstrated between the contractile motor activity and the increase in the diameter of the coronary arteries ${ }^{4}$.

Finally, it has been demonstrated that Kabat's PNF physiotherapeutic techniques sufficiently increase the tension of the vascular friction stimulus to increase the capacity of transport of the L-arginine (L-Arg), which is the precursor of the NO molecule, and they also increase the activity and expression of the nitric oxide synthase. All this leads to an increase in the endothelial production of NO, a vasodilating substance produced by the vascular endothelium responsible for these hemodynamic changes and of the consequent vasodilation observed in this case report.

Conflict of interest. None of the authors has conflicts of interest related to this study.

\section{REFERENCES}

1. Voss D, Ionta M, Myers B. Facilitación neuromuscular propioceptiva. Patrones y técnicas. $3^{\mathrm{a}}$. ed en español. Buenos Aires: Médica Panamericana SA; 1987. p. 409.

2. Torres AI, Basco JA, Morales A, Molina MI. El método de Kabat y la lesión medular espinal. Fisioterapia. 2003; 1: 2-11.

3. Correti CM, Anderson TJ. Guidelines for the ultrasound assessment of endothelial-dependent flow-mediated vasodilation of the brachial artery: A report of the International Brachial Artery Reactivity Task Force. J Am Coll Cardiol. 2002; 39: 257-65.

4. Willich SN, Lewis M, Lowel H, Arntz HR, Schubert F, Schröder R. Physical exertion as a trigger of acute myocardial infarction. N Engl J Med. 1993; 329: 1684-90.

5. Manoel ME, Harris-Love MO, Danoff JV, Miller TA. Acute effects of static, dynamic, and proprioceptive neuromuscular facilitation stretching on muscle power in women. J Strength Cond Res. 2008; 22: 1528-34. 